\title{
Extraocular muscle injury during endoscopic sinus surgery: A series of 10 cases at a single center*
}

\author{
Jung Hyeob Sohn 1,"\#, Sang Duk Hong,"\#, Joon Ho Kim², Hun-Jong Dhong1, \\ Seung-Kyu Chung', Hyo Yeol Kim', Sei Yeul Oh³ \\ Rhinology 52: 238-245, 2014 \\ DOI:10.4193/Rhino13.131 \\ ' Department of Otorhinolaryngology - Head and Neck Surgery, Samsung Medical Center, Sungkyunkwan University School of \\ *Received for publication: \\ Medicine, Seoul, Korea \\ August 28, 2013 \\ ${ }^{2}$ Hana ENT Hospital, Seoul, Korea \\ Accepted: January 26, 2014
}

${ }^{3}$ Department of Ophthalmology, Samsung Medical Center, Sungkyunkwan University School of Medicine, Seoul, Korea

\begin{abstract}
Background: Extraocular muscle (EOM) injury is a rare but serious complication of endoscopic sinus surgery (ESS). The aim of this study is to describe the clinical characteristics and course of EOM injury occurring during ESS.
\end{abstract}

Design: Retrospective case series.

Methods: Medical records and CT images of patients who suffered from EOM injury after ESS between 2006 and 2012 were retrospectively reviewed. Patient demographics, endoscopic anatomy, type of surgery (primary or revision), predisposing risk factors, site and extent of injury on CT imaging, and associated complications were evaluated. In addition, data regarding ophthalmologic management and clinical outcomes were collected.

Results: Ten patients with EOM injuries after ESS were included in this study. One patient was undergoing revision ESS. All patients sustained medial rectus muscle injury and one patient suffered concurrent ipsilateral inferior rectus muscle injury. A microdebrider was used in nine cases. Right-sided injury (90\% of patients) was more prevalent than left-sided injury, and $70 \%$ of injured medial rectus muscles were completely transected. After subsequent strabismus surgery, 8/9 patients regained binocular single vision in primary gaze despite residual diplopia in some gaze positions.

Conclusion: Although proper ophthalmologic surgery after EOM injury may improve deviation in the primary gaze position, none of the patients regained normal EOM movement. Therefore, prevention of this complication through adequate surgical technique and precautions is important.

Key words: endoscopic sinus surgery, microdebrider, rhinosinusitis, complications, extraocular muscle injury, diplopia, strabismus, medial rectus muscle, orbit

\section{Introduction}

Endoscopic sinus surgery (ESS) is well-established as the mainstay of surgical treatment for refractory paranasal sinusitis. However, the proximity of the paranasal sinuses to the orbit and their anatomical complexity put the orbital contents at risk of injury during surgery ${ }^{(1)}$. In addition, use of the microdebrider, which provides a powerful and efficient means of tissue resec- tion, can be another source of injury if the suction cutting tip is misdirected into the orbit. This is especially risky during ethmoid sinus surgery performed by a less experienced surgeon ${ }^{(2)}$.

Orbital complications of ESS include periorbital ecchymosis with injury to the lamina papyracea, retrobulbar hematoma, extraocular muscle (EOM) injury, optic nerve injury, nasolacrimal duct 
injury, and formation of an orbital abscess ${ }^{(3-5)}$. Among these problems, EOM injury is rare but serious because of its poor prognosis and complicated course of management ${ }^{\left({ }^{6}\right)}$. Several

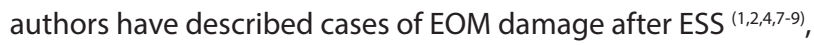
however, many of these studies are case reports with limited data on rescue strabismus surgery.

The aim of the present study is to characterize the clinical course of EOM injury occurring during ESS and to evaluate risk factors for injury during the procedure. Additionally, we will evaluate prognosis after rescue management.

\section{Materials and methods}

This is a single-center observational study that included 10 patients who experienced strabismus after ESS. Patients who were referred to our hospital with confirmed EOM injury after ESS from January 2006 to August 2012 were enrolled in our study. After obtaining approval from the Institutional Ethics Committee, we retrospectively reviewed medical records of these patients. Demographic data, preoperative diagnoses, surgical status (revision versus primary), grade of hospital where surgery was performed, and clinical course were analyzed. In addition, available preoperative and postoperative imaging (computed tomography [CT] and/or magnetic resonance imaging [MRI]) data were evaluated. Using pre- and postoperative images, predisposing risk factors for orbital injury, extent of sinus surgery, size and site of the damaged lamina papyracea, involvement of EOM and extent of injury, and presence of concurrent orbital complications were interpreted.

The results of general ophthalmic examinations were analyzed. The deviated angles of the affected eyes were measured using a corneal reflex test (Hirschberg test) performed in the primary position, and are expressed as prism diopters (PD). The adduction deficits ranged from 0 to -4 , with $0,-1,-2,-3$, and -4 indicating $100 \%, 75 \%, 50 \%, 25 \%$, and $0 \%$ of full adduction, respectively. Forced duction tests (FDTs) were performed to determine mechanical restriction. Patterns of injury on MRI were defined according to a previous report ${ }^{(10)}$, which described four categories of injury: pattern I (medial rectus [MR] complete transection) showing large-angle exotropia (>25 PD) and marked adduction deficits with relatively intact abduction and little or no entrapment, pattern II (partial MR transection or severe contusion) showing a moderate-to large-angle exotropia with combined adduction and abduction deficits in most cases, and patterns III (grossly intact or modestly contused muscle) and IV (mild muscle contusion without entrapment) showing mild contusions with an intact MR muscle.

After comprehensive ophthalmic examination, patients underwent individualized repair performed by a single expe- rienced ophthalmologic surgeon (SYO). Prognosis after rescue treatments were determined based on deviation angles and adduction ability during the follow-up period.

\section{Results}

A total of 10 patients who presented to our institution between 2006 and 2012 were included in this study. All patients had previously undergone ESS at an external hospital or clinic. Eight of the patients were men and two were women, with a mean age of 47.2 years (range, 20-64 years). The mean follow-up period after initial injury was 30.3 months (range, 16-69 months).

Nine patients had been diagnosed with chronic rhinosinusitis and one with a fungal ball. One patient with rhinosinusitis was undergoing revision surgery. Right-sided injury was more prevalent ( 9 of 10 patients) than left-sided injury. Seven patients were referred from primary care clinics, two were sent from a tertiary hospital, and one patient was referred from a military hospital. All EOM injuries were unilateral, although bilateral surgery was performed in four cases (Table 1). Use of the microdebrider was documented during ESS in nine cases (90\%), and it was believed that the microdebrider was also used in the remaining case despite no obvious record of surgical instruments used. EOM damage was recognized intraoperatively in four cases and postoperatively in six cases.

Imaging findings associated with EOM injuries are listed in Table 2. CT scans revealed a bony defect of the lamina papyracea, which varied in size from 11-21 mm on the axial view. There were seven cases of mid-posterior wall defects and two cases of anterior-mid wall defects. Another patient (case 3) exhibited a large anterior to posterior defect. In most cases, defects of the lamina papyracea were observed near or at the lateral attachment site of the vertical plate of the basal lamella, which was used as a central landmark during ethmoid sinus surgery ${ }^{(11)}$. All patients suffered medial rectus muscle injuries, and one patient also experienced concurrent inferior rectus muscle injury. Two contralateral dehiscences in the lamina papyracea were confirmed on CT imaging. Four patients were found to have a deviated nasal septum, though only one had septal deviation toward the affected side.

All patients had large-angle exotropia (>30 PD) with prominent dysfunction of adduction and mild or no restriction on FDT (Table 3). These findings were consistent with pattern I injury (complete transection). However, seven subjects (70\%) were confirmed as having a pattern I MR injury according to the obvious discontinuity of muscle bulk on CT scans, whereas the other three cases were categorized as pattern II injuries (partial transection) on imaging. The extent of muscle injury, such as complete or partial transection, defect size and site within the 
Table 1. Patient characteristics.

\begin{tabular}{|c|c|c|c|c|c|c|c|}
\hline Case & Age/gender & Primary hospital & Diagnosis & Injury side & OP name & Revision & $\begin{array}{c}\text { Use of } \\
\text { microdebrider }\end{array}$ \\
\hline 1 & $20 / M$ & Military & CRS (R) & Right & EMMA (R) & No & Yes \\
\hline 2 & $46 / F$ & Tertiary & Fungus ball (R) & Right & EMMA (R) & No & Yes \\
\hline 3 & $64 / F$ & Private clinic & CRS (B) & Left & EMMA (L) & No & Yes \\
\hline 4 & $49 / \mathrm{M}$ & Private clinic & CRS (R) & Right & EMMA (R) & No & - \\
\hline 5 & $45 / \mathrm{M}$ & Tertiary & CRS (B) & Right & EMMA (B) & Yes & Yes \\
\hline 6 & $46 / M$ & Private clinic & CRS (R) & Right & EMMA (R) & No & Yes \\
\hline 7 & $44 / M$ & Private clinic & CRS (B) & Right & EMMA (R) & No & Yes \\
\hline 8 & $36 / M$ & Private clinic & CRS (B) & Right & EMMA (B) & No & Yes \\
\hline 9 & $61 / M$ & Private clinic & CRS (B) & Right & EMMA (B) & No & Yes \\
\hline 10 & $61 / M$ & Private clinic & CRS (B) & Right & EMMA (B) & No & Yes \\
\hline
\end{tabular}

CRS = chronic rhinosinusitis; EMMA = ethmoidectomy and middle meatal antrostomy; $B=$ both; $R=$ right; $L=$ left.

Records from case 4 contained no information regarding surgical instrumentation.

Table 2. Imaging findings of orbital injury after ESS.

\begin{tabular}{|c|c|c|c|c|c|c|c|c|}
\hline Case & $\begin{array}{l}\text { Size of } \\
\text { LP defect } \\
(\mathrm{mm})\end{array}$ & $\begin{array}{l}\text { Site of LP } \\
\text { defect }\end{array}$ & $\begin{array}{l}\text { Muscle } \\
\text { involved }\end{array}$ & Type of injury & $\begin{array}{l}\text { Length of } \\
\text { anterior } \\
\text { stump (mm) }\end{array}$ & $\begin{array}{l}\text { Length of } \\
\text { muscle loss } \\
\text { (mm) }\end{array}$ & $\begin{array}{c}\text { Other } \\
\text { complications }\end{array}$ & Other findings \\
\hline 1 & 12 & Mid-posterior & Medial rectus & $\begin{array}{l}\text { Complete } \\
\text { resection }\end{array}$ & 14.0 & 16.7 & None & $\begin{array}{c}\text { Septal deviation toward } \\
\text { contralateral side }\end{array}$ \\
\hline 2 & 11 & Anterior-mid & Medial rectus & $\begin{array}{l}\text { Complete } \\
\text { resection }\end{array}$ & 10.0 & 13.0 & None & $\begin{array}{l}\text { Contralateral } \\
\text { LP dehiscence }\end{array}$ \\
\hline 3 & 21 & Ant-posterior & Medial rectus & $\begin{array}{l}\text { Partial } \\
\text { resection }\end{array}$ & Partial los & (anterior) & None & $\begin{array}{l}\text { Hypoplastic } \\
\text { maxillary sinus }\end{array}$ \\
\hline 4 & 17 & Anterior-mid & Medial rectus & $\begin{array}{l}\text { Complete } \\
\text { resection }\end{array}$ & 12.6 & 10.9 & None & $\begin{array}{c}\text { Septal deviation toward } \\
\text { affected side }\end{array}$ \\
\hline 5 & 13 & Mid-posterior & Medial rectus & $\begin{array}{l}\text { Partial } \\
\text { resection }\end{array}$ & Partial loss & (posterior) & CSF leakage & Revision case \\
\hline 6 & 12 & Mid-posterior & Medial rectus & $\begin{array}{l}\text { Complete } \\
\text { resection }\end{array}$ & 23.7 & 9.2 & $\begin{array}{c}\text { Orbital } \\
\text { haemorrhage }\end{array}$ & $\begin{array}{l}\text { Contralateral LP dehis- } \\
\text { cence and } \\
\text { septal deviation }\end{array}$ \\
\hline 7 & 11 & Mid-posterior & Medial rectus & $\begin{array}{l}\text { Complete } \\
\text { resection }\end{array}$ & 22.7 & 9.5 & None & Nonspecific \\
\hline 8 & 12 & Mid-posterior & Medial rectus & $\begin{array}{l}\text { Partial } \\
\text { resection }\end{array}$ & \multicolumn{2}{|c|}{ Partial loss (middle) } & Vision loss & Nonspecific \\
\hline 9 & 14 & Mid-posterior & Medial rectus & $\begin{array}{l}\text { Complete } \\
\text { resection }\end{array}$ & 23.8 & 7.9 & None & Nonspecific \\
\hline 10 & 12 & Mid-posterior & $\begin{array}{l}\text { Medial rectus } \\
\text { Inferior rectus }\end{array}$ & $\begin{array}{l}\text { Complete } \\
\text { resection }\end{array}$ & 17.2 & 14.3 & None & $\begin{array}{c}\text { Septal deviation toward } \\
\text { contralateral side }\end{array}$ \\
\hline
\end{tabular}

LP = lamina papyracea; CSF = cerebrospinal fluid; ESS = endoscopic sinus surgery 
Table 3. Summary of findings on initial ophthalmic evaluation.

\begin{tabular}{|c|c|c|c|c|}
\hline Case & Vision & Adduction & $\begin{array}{l}\text { Angle of } \\
\text { exotropia }\end{array}$ & FDT \\
\hline 1 & 0.6 & -3 & 30PD XT & no restriction \\
\hline 2 & 0.6 & -4 & 50PD XT & no restriction \\
\hline 3 & 0.1 & -2 & 45PD XT & $\begin{array}{l}\text { med. \& lat. rectus: } \\
\text { mild restriction (+) }\end{array}$ \\
\hline 4 & 1.0 & -4 & $30 \mathrm{PD} \times \mathrm{T}$ & no restriction \\
\hline 5 & 0.1 & -4 & 45PD XT & no restriction \\
\hline 6 & 0.6 & -4 & 80PD XT & no restriction \\
\hline 7 & 0.5 & -4 & $60 \mathrm{PD} \times \mathrm{XT}$ & no restriction \\
\hline 8 & 0.04 & -3 & 35PD XT & $\begin{array}{l}\text { med. rectus: } \\
\text { mild restriction (+) }\end{array}$ \\
\hline 9 & 0.2 & -4 & 50PD XT & no restriction \\
\hline 10 & 0.8 & -4 & 80PD XT & no restriction \\
\hline
\end{tabular}

$\mathrm{IOP}=$ intraocular pressure; $\mathrm{D} \& \mathrm{~V}=$ duction and version; $\mathrm{FDT}=$ forced duction test; $\mathrm{XT}=$ exotropia.

Table 4. Methods and results of ophthalmic management. lamina papyracea, and presence of other orbital complications, had no effect on the severity of strabismus or motility impairment of the EOM.

Unfortunately, some patients experienced additional complications associated with the extraocular muscle injury. One patient (case 8) experienced vision loss due to optic nerve damage. This complication was presumed to be due to removal of sphenoethmoidal cells along a prominently hanging optic nerve that was not identified by the primary surgeon. In addition, another patient (case 5) suffered from cerebrospinal fluid leakage due to combined skull base injury, which improved with 1 week of conservative management. In case 6, EOM injury was associated with immediate retrobulbar haemorrhage. Initial tonometry of the right eye showed an intraocular pressure (IOP) of $98 \mathrm{mmHg}$. Emergent canthotomy and cantholysis were performed, and systemic corticosteroids and mannitol were also used to reduce the IOP. The IOP normalized after these interventions but a mild visual field defect remained.

Nine patients underwent strabismus surgery. The remaining patient is waiting for the optimal ophthalmic surgical time when the exotropia angle and adductor function have stabilized. The degree of the exotropia angle was the single most important

\begin{tabular}{|c|c|c|c|c|c|}
\hline Case & Major intervention & $\begin{array}{c}\text { Number } \\
\text { of operations }\end{array}$ & Exotropia angle & Adduction & $\begin{array}{l}\text { F/U period*** } \\
\text { (months) }\end{array}$ \\
\hline 1 & $R \& R$ & 5 & 15 PD XT (OD) & -3 & 29 \\
\hline 2 & $\begin{array}{l}\text { Muscle transposition } \\
\text { Lateral rectus recession }\end{array}$ & $6^{*}$ & $\begin{array}{c}6 \text { PD XT } \\
\text { (OD) }\end{array}$ & -2 & 38 \\
\hline 3 & $R \& R$ & 3 & 0 PD XT (OS) & -2 & 18 \\
\hline 4 & $R \& R$ & 1 & 0 PD XT (OD) & -2 & 53 \\
\hline 5 & $\begin{array}{l}\text { MR anchoring with } \\
\text { microplate } \\
\text { Lateral rectus recession }\end{array}$ & 2 & 6 PD XT (OD) & -1 & 21 \\
\hline 6 & $R \& R$ & 1 & 0 PD XT (OD) & -1 & 20 \\
\hline 7 & $R \& R$ & 1 & 0 PD XT (OD) & -0.5 & 21 \\
\hline 8 & $\begin{array}{l}\text { Muscle transposition } \\
\text { Lateral rectus recession }\end{array}$ & 2 & 0 PD XT (OD) & -2 & 69 \\
\hline 9 & $\begin{array}{l}\text { Muscle transposition } \\
\text { Lateral rectus recession }\end{array}$ & 1 & 0 PD XT (OD) & -2 & 8 \\
\hline 10 & & 0 & $\begin{array}{l}50 \text { PD XT (OD) } \\
10 \text { PD RHT (OD) }\end{array}$ & -4 & 3 \\
\hline
\end{tabular}

* Including immediate muscle repair; ** Time from initial injury to final follow-up.

$R \& R=$ medial rectus muscle resection and lateral rectus muscle recession; $P D=$ prism diopter; $X T=$ exotropia; $O D=$ right eye; $O S=$ left eye. 


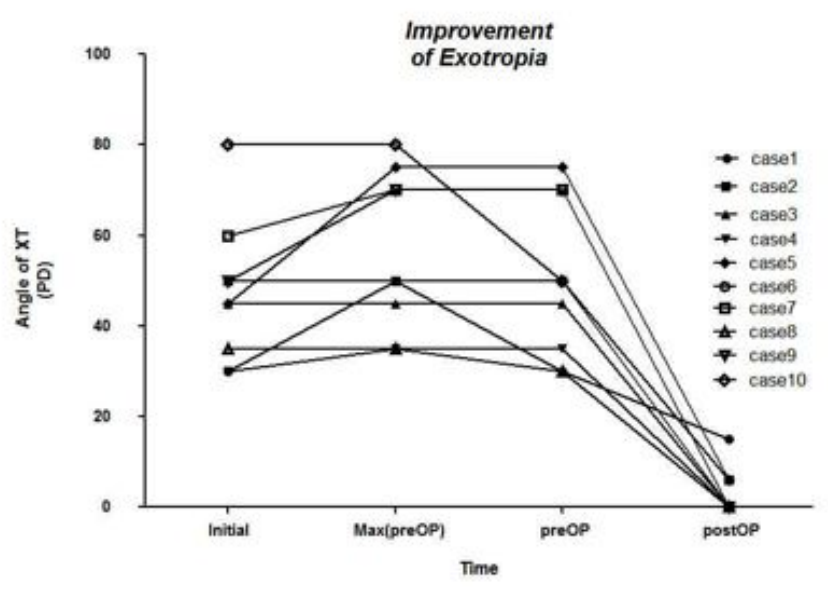

Figure 1. Angle of exotropia of the damaged eyes initially, preoperatively, and postoperatively. Most patients exhibited marked improvement over time.

factor in determining treatment plan and projected outcomes. On average, 7 months elapsed between the initial injury and subsequent surgical management. During the follow-up period, four patients (40\%) showed changes in the angle of exotropia (Figure 1). Five patients underwent resection of the involved MR muscle and recession of its antagonist muscle (lateral rectus muscle). Three patients underwent vertical rectus muscle transposition, and the remaining patient underwent MR muscle anchoring using a microplate together with recession of the lateral rectus muscle. Cases 3 and 5 also underwent postoperative orbital exploration 1 and 2 months after surgery, respectively, because of $\mathrm{CT}$ findings indicating that the remaining posterior stump of the involved muscle was long. However, tissue loss from the injured muscle and inflammation and fibrosis around the site of injury was so severe that direct reconnection of the muscle stumps was not possible. Five patients underwent multiple surgeries, and two of these (cases 1 and 2) underwent more than five operations. After the final surgery, all patients demonstrated minimal or no exotropia in primary gaze (Figure 1). In eight cases (88.9\%), adduction of the involved eye was improved to less than -2 , which means that $50 \%$ of full adduction was achieved (Table 4). Most subjects expressed satisfaction and quickly adapted to their condition, and three of them were even able to drive a car without difficulty (Figure 2).

\section{Discussion}

EOM injury during ESS may result in diplopia that is therapeutically challenging. This complication is seldom surgically reparable, and outcomes are known to be generally poor ${ }^{(2)}$. Diplopia resulting from ESS is very rare ${ }^{(12)}$, and as a result most reports of EOM injury associated with ESS are small case series of two or three patients. There are few studies examining long-term postoperative follow-up. Huang et al. ${ }^{(10)}$ published the largest series to date regarding MR muscle injuries related to ESS. However, because they included 30 patients from 10 different hospitals, their treatment methods and postoperative follow-up were not uniform. In the present study, we reviewed 10 cases managed by a single ophthalmologic surgeon (SYO). The mean follow-up period was 28 months after the initial injury and 23 months after initial strabismus management. Thus, our findings are notable as they are the only dataset collected from a single center that includes long-term follow-up.

The MR muscle has been reported to be the most frequently damaged EOM during ethmoid sinus surgery ${ }^{(10,13,14)}$. In this study, all 10 cases involved the MR muscle, with involvement of the posterior half of the muscle in $70 \%$ of patients. The MR muscle originates from the annulus of Zinn and travels along the medial aspect of the globe, ultimately inserting on the sclera. As the

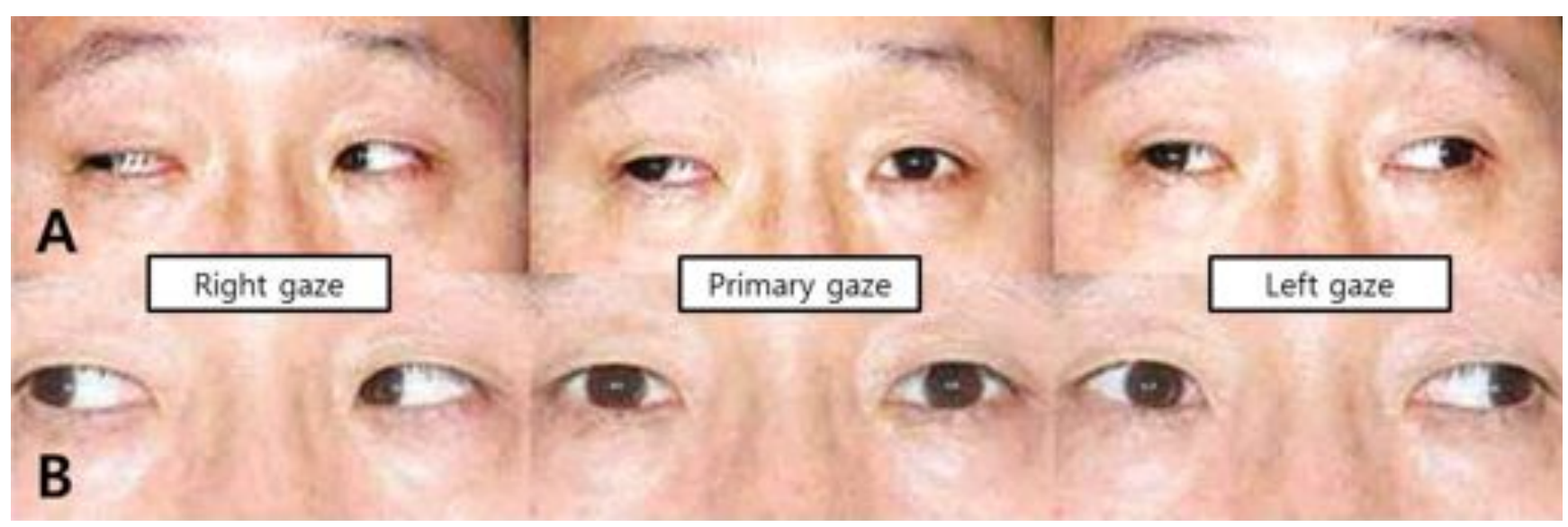

Figure 2. Clinical photographs of case 7. (A) Preoperatively, marked exotropia and marked adduction deficiency in left-sided gaze were observed. (B) Postoperatively, orthophoria in the primary position and better adduction ability of the right eye were observed. 
muscle travels anteriorly, it takes a slightly lateral course away from the lamina papyracea ${ }^{(15)}$. As a result, there is a fatty layer between the MR muscle and the lamina papyracea in the anterior part of ethmoid sinus and little fat in the posterior ethmoid sinus. Consequently, MR muscle injuries may be increased in the posterior ethmoid sinus due to the absence of fat herniation, which may serve as a warning sign of lamina papyracea damage.

Complication rates during ESS may be higher in patients with diffuse nasal polyps or a severely deviated nasal septum, which could restrict the surgical view ${ }^{(9)}$. This could not be confirmed in the present study, because only one patient had septal deviation toward the affected side and there were no records of the extent of disease. Therefore, surgeons, especially those with less experience, must confirm the tip position of the instruments multiple times during ethmoid sinus surgery and should not perforate any septae within the ethmoid sinus without first confirming the posterior space, irrespective of septal deviation or extent of disease.

In Korea, the majority of ESS procedures are performed in tertiary hospitals although some are performed by surgeons in private clinics who might have less experience of performing this surgery. Since $70 \%$ of cases in this study were referred from private clinics, education and warning about the risk of EOM injury during ESS is vital, and it cannot be emphasized enough that adequate and proper training is essential before performing ESS.

It is also noteworthy that most of the patients (9 cases) enrolled in this study were affected on the right side. In previous reports ${ }^{(6)}$, the right eye was involved in $73 \%$ of cases. This is probably because right-handed surgeons have a more difficult time finding the boundary of the right lamina papyracea, and the tip of the instrument within the right nasal cavity is more likely to direct itself into the lamina papyracea ${ }^{(16)}$.

The microdebrider is an important refinement of an endoscopic surgical tool that provides powered dissection. However, because of the suction component of the instrument, tissue can instantly be drawn into the rotating blades. As a consequence, the risk of injury is higher with the microdebrider than with conventional instruments and such damage is typically not reparable through orbital exploration ${ }^{(2)}$. In general, if a powered dissector is used without due caution or in cases of anatomical variability such as Haller cells, Onodi cells, hypoplastic maxillary sinuses, or natural dehiscence of the lamina papyracea, the risk of orbital complications may increase ${ }^{(1,4)}$.

In the largest case series of MR injuries occurring during ESS (30 cases at 10 centers), Huang et al. ${ }^{(10)}$ described four patterns of
Table 5. Number of total transections of the medial rectus muscle after endoscopic sinus surgery reported in previous studies.

\begin{tabular}{|c|c|c|}
\hline Author & Number of cases & $\begin{array}{l}\text { Number of total } \\
\text { transections, } \mathbf{n}(\%)\end{array}$ \\
\hline Neuhaus et al., $1989^{(19)}$ & 3 & $0(0 \%)$ \\
\hline Penne et al., $1993^{(14)}$ & 1 & $1(100 \%)$ \\
\hline Trotter et al., $2000^{(7)}$ & 2 & $2(100 \%)$ \\
\hline Bhatti et al., $2001^{(1)}$ & 2 & $1(50 \%)$ \\
\hline Ling et al., $2001^{(20)}$ & 1 & $1(100 \%)$ \\
\hline Huang et al., $2003^{(10)}$ & 30 & $8(26.7 \%)$ \\
\hline Kim et al., $2004^{(9)}$ & 3 & $0(0 \%)$ \\
\hline Thacker et al., $2005^{(13)}$ & 14 & $6(42.9 \%)$ \\
\hline Levy et al., $2005^{(21)}$ & 1 & $0(0 \%)$ \\
\hline Total & 57 & $19(33.3 \%)$ \\
\hline
\end{tabular}

injury. Among them, treatment of type I (total transection) and type II (partial transection or severe contusion) injuries was the most challenging. Sixty-three cases of ocular motility complications during ESS have been reported, 57 of which included information on the mechanism of injury (Table 5). Among these 57 cases, only 19 (33\%) suffered total transection injuries, which are the most difficult to manage. In our study, seven (70\%) patients experienced total transection (type I) and three had partial transection (type II) injuries. It is not clear why the incidence of severe EOM injuries was higher in the current study. Over the last decade, ESS has become a popular surgery in Korea. However, many surgeons are inexperienced with this technique, and use of the microdebrider can result in more severe EOM injury $(1,2)$. In this study, the microdebrider was used in all nine patients for whom details regarding instrumentation were available.

The purpose of surgical management of MR injury during ESS is to correct exotropia and improve ocular alignment in the primary gaze position, as well as to restore adductor function ${ }^{(8)}$. It should also be considered to help limit fibrosis and contracture of the antagonistic musculature ${ }^{(10,17)}$. In the setting of complete transection, early direct reanastomosis is recommended if the posterior $20 \mathrm{~mm}$ of the muscle stump is present and functional. Therefore, orbital exploration may be considered in cases that are identified within a few days of the injury and in which the remaining posterior stump is long. Unfortunately, in many cases the amount of muscle loss related to muscle contracture and damage caused by instrumentation may hamper primary 


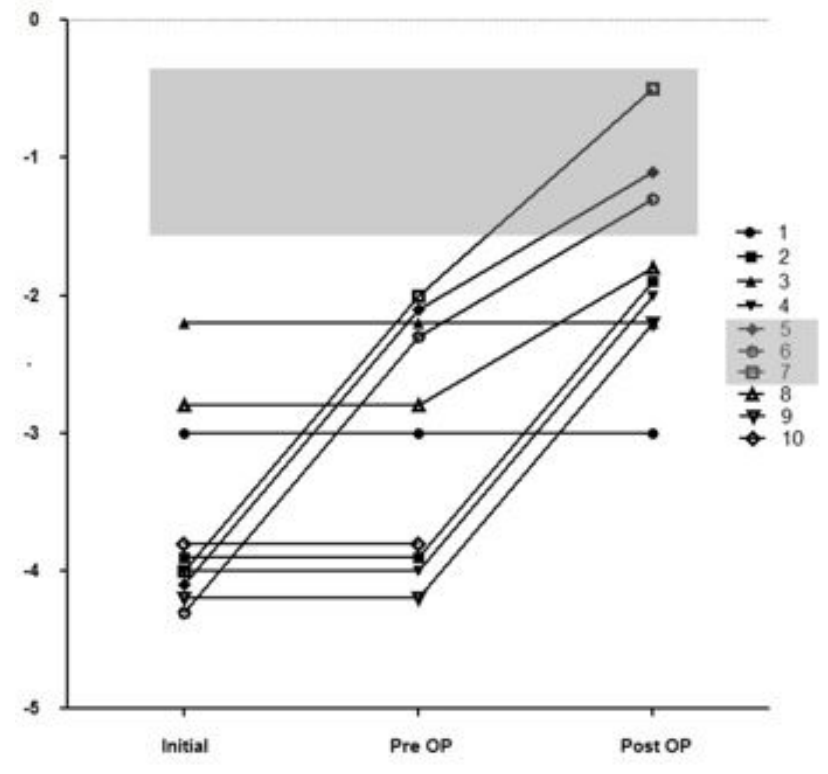

Figure 3. Adductor function of the involved medial rectus muscle.

reanastomosis ${ }^{(13)}$ because MR damage due to powered cutting instruments is known to be difficult to repair through orbital exploration (2).

The present study included seven cases of complete transection and three cases of partial resection of MR muscle after ESS. In these patients, radiological findings showed interrupted muscle contour and loss of muscle burden. On ophthalmological examination, patients initially had large-angle exotropia with a marked inability to adduct the eye. Surgical techniques, such as resection, recession, reposition of the MR muscle, or muscle transposition from the superior or inferior rectus muscles, were used as alternatives when primary reanastomosis was not possible. These approaches can advance ocular alignment in the primary gaze and reinforce function of the injured EOM. In the current study, most patients achieved acceptable levels of diplopia and exotropia in primary gaze. Moreover, eight of the patients displayed improved adductor function of the injured MR muscle. These results were particularly pronounced in three patients who exhibited improvements in medial gaze before ophthalmological surgery (complete resection in two and partial resection in one) (Figure 3). It is likely that spontaneous improvement in adductor function was due to the formation of new muscle insertion sites as a result of fibrotic change around the injured lamina papyracea, in addition to an intact neurovascular supply despite MR transection since the inferior branch of the occulomotor nerve innervates the antero-medial surface of the $M R^{(18)}$.
MR injury is a devastating orbital complication of ESS with a poor prognosis. Powered cutting instruments can contribute to the potential for EOM injury of greater severity. Despite subsequent surgical management, residual diplopia and adductor dysfunction may be permanent and can drastically affect activities of daily living. The primary goal of salvage strabismus surgery is orthophoria in primary gaze, although dynamic functional recovery of the injured muscle is also important. Even in cases of complete transection and loss of a large burden of MR muscle, aggressive and proper salvage management may result in single binocular vision in primary gaze. In the current study, all patients except for one achieved <10 PD exotropia with single binocular vision in primary gaze, although with some remaining adductor dysfunction.

Prevention of EOM injury during ESS is an important consideration, especially for inexperienced surgeons or those using a microdebrider near the lamina papyracea. Powered instruments should always be used conservatively, placing the opening of the blade at a $90^{\circ}$ angle to the orbital wall and dissecting superiorly or inferiorly. Repeated identification of anatomical landmarks in the nasal cavity during ESS along with careful inspection of preoperative $\mathrm{CT}$ imaging is also recommended. Most importantly, however, the microdebrider must never be used blindly.

\section{Conclusion}

The importance of preventing EOM injury in ESS cannot be overemphasized, especially when using a microdebrider, because extraocular function rarely returns to normal despite appropriate ophthalmological surgeries.

\section{Authorship contribution}

JHS: collected data, wrote article; SDH: study conception and design, acquisition of data, analysis and interpretation of data, drafting the article and revisions, final approval of article; JHK: analysis and interpretation of data, drafting the article and revisions; HJD: study conception and design, drafting the article and revisions, final approval of article; SKC: analyzed data, revised article; HYK: analyzed data, revised article; SYO: analyzed data, revised article

\section{Conflict of interest}

The authors have no conflict of interest to declare. 


\section{References}

1. Bhatti MT, Giannoni CM, Raynor E, Monshizadeh R, Levine LM. Ocular motility complications after endoscopic sinus surgery with powered cutting instruments. Otolaryngol Head Neck Surg. 2001; 125 501-509.

2. Graham SM, Nerad JA. Orbital complications in endoscopic sinus surgery using powered instrumentation. Laryngoscope. 2003; 113: 874-878.

3. Han JK, Higgins TS. Management of orbital complications in endoscopic sinus surgery. Curr Opin Otolaryngol Head Neck Surg. 2010; 18: 32-36

4. Rene C, Rose GE, Lenthall R, Moseley I. Major orbital complications of endoscopic sinus surgery. Br J Ophthalmol. 2001; 85: 598-603.

5. Carton A, Hislop S. Orbital floor injury with extraocular muscle entrapment following functional endoscopic sinus surgery. $\mathrm{Br} J$ Oral Maxillofac Surg. 2000; 38: 82-83.

6. Thacker NM, Velez FG, Demer JL, Rosenbaum AL. Strabismic complications following endoscopic sinus surgery: diagnosis and surgical management. J AAPOS 2004; 8: 488-494.

7. Trotter WL, Kaw P, Meyer DR, Simon JW Treatment of subtotal medial rectus myectomy complicating functional endoscopic sinus surgery. J AAPOS. 2000; 4: 250-253.

8. Cho YA, Rah SH, Kim MM, Lee JY. Vertica rectus muscles transposition in large exotropia with medial rectus muscle transection following endoscopic sinus surgery. Korean J of Ophthalmol. 2008; 22: 104-110.
9. Kim HJ, Kim CH, Song MS, Yoon JH. Diplopia secondary to endoscopic sinus surgery. Acta Otolaryngol. 2004; 124: 1237-1239.

10. Huang CM, Meyer DR, Patrinely JR, et al. Medial rectus muscle injuries associated with functional endoscopic sinus surgery: characterization and management. Ophthal Plast Reconstr Surg. 2003; 19: 25-37.

11. Sargi ZB, Casiano RR. Surgical Anatomy of the Paranasal sinuses. In: Kountakis SE, Önerci M, eds. Rhinologic and Sleep Apnea Surgical Techniques. Berlin, Germany: Springer-Verlag, 2007; 17-26.

12. Cumberworth VL, Sudderick RM, Mackay IS. Major complications of functional endoscopic sinus surgery. Clin Otolaryngol Allied Sci. 1994; 19: 248-253.

13. Thacker NM, Velez FG, Demer JL, Wang MB, Rosenbaum AL. Extraocular muscle damage associated with endoscopic sinus surgery: an ophthalmology perspective. Am J Rhinol. 2005; 19: 400-405.

14. Penne RB, Flanagan JC, Stefanyszyn MA Nowinski T. Ocular motility disorders secondary to sinus surgery. Ophthal Plast Reconstr Surg. 1993; 9: 53-61.

15. Bleier BS, Schlosser RJ. Prevention and management of medial rectus injury. Otolaryngol Clin North Am. 2010; 43: 801807.

16. Vleming $M$, Middelweerd RJ, de Vries $N$ Complications of endoscopic sinus surgery. Arch Otolaryngol Head Neck Surg. 1992; 118: 617-623

17. Hong JE, Goldberg AN, Cockerham KP. Botulinum toxin A therapy for medial rectus injury during endoscopic sinus surgery. Am
J Rhinol. 2008; 22: 95-97

18. Yanoff M, Duker JS. In: Ophthalmology. 3rd ed. Philadelphia, PA: Mosby Elsevier, 2008; 1303.

19. Neuhaus RW. Orbital complications secondary to endoscopic sinus surgery. Ophthalmology. 1990; 97: 1512-1518.

20. Ling R, Quinn AG. Traumatic rupture of the medial rectus muscle. J AAPOS. 2001; 5: 327-328.

21. Levy J, Lifshitz T, Monos T, Puterman M Biedner BZ. Medial rectus muscle injury complicating functional endoscopic sinus surgery. Isr Med Assoc J. 2005; 7: 270-271.

\author{
Dr. Hun-Jong Dhong \\ Department of Otorhinolaryngology \\ - Head and Neck Surgery \\ Samsung Medical Center \\ Sungkyunkwan University School of \\ Medicine \\ 50 Irwon-Dong \\ Gangnam-Gu \\ Seoul, 135-710 \\ Korea
}

Tel.: +82-2-3410-3579,

Fax: +82-2-3410-3879

E-mail: hjdhong@skku.edu 